\title{
Sustainability, Energy and Development: A Proposal of Indicators
}

\author{
Aurora Carneiro Zen ${ }^{3}$, Adroaldo Lima ${ }^{1}$, André Luis Bianchi ${ }^{1,2}$, Lorena Babot ${ }^{1}$ \\ ${ }^{1}$ NBN Projetos e Consultoria em Sistemas Eficientes Ltda \\ ${ }^{2}$ Universidade Luterana do Brasil - ULBRA \\ ${ }^{3}$ Federal University of Rio Grande do Sul - UFRGS
}

\begin{abstract}
Measuring sustainability is a major issue as well as a driving force for the discussion on sustainable development. Developing tools that reliably measure sustainability is a prerequisite for identifying non-sustainable processes informing design-makers of products' quality and monitoring impacts on the social environment. According to Agenda 21, one of these significant issues to sustainability is energy. This paper presents a proposal of sustainable energy indicators for cities. This research presents 26 indicators classified into five dimensions (environmental, economic, social, territorial and political). The indicators were validated by experts of different fields who also gave weights for each indicator depending on its importance to sustainability. This resulted in the finding of key indicators in each dimension. The analysis of these five dimensions could help policymakers to foster sustainable energy development in the cities. This research was conducted in the Brazilian context, an emerging economy. In these economies, sustainable energy has become central to maintain the country's growth. The result of this research is the first step in order to develop an index of sustainable energy of cities. Further research should apply these indicators to evaluate cities in different contexts.
\end{abstract}

\section{Introduction}

'Sustainable development' has been best defined by the Brundtland Commission as the 'development that meets the needs of the present without compromising the ability of future generations to meet their own needs' [1]. Achieving sustainable economic development on a global scale will require the judicious use of resources, technology, appropriate economic incentives and strategic policy planning at the local and national levels. It will also require continuous monitoring on the impacts of selected policies and strategies to distinguish whether they are fostering sustainable development or should be adjusted. It is important to measure a city's level of sustainable development and to monitor its progress towards sustainability. When choosing energy fuels and related technologies for production, delivery and use of energy services, it is essential to take into account economic, social and environmental consequences. Policymakers need methods for measuring and assessing the current and future effects of energy use on human health, human society, air, soil and water. They need to determine whether current energy use is sustainable and, if not, how to change it in order to become [2].

In sum, the sustainable indicators point a direction for the development of certain practices and / or policies. Moreover, the set of indicators can serve as instruments of prediction [3]. This paper presents a set of sustainable energy indicators of cities considering five dimensions: the economic, social, environmental, territorial and political dimensions [4].

\section{Energy and Sustainable Development}

Agenda 21, the Rio Declaration on Environment and Development, was adopted by the United Nations Conference on Environment and Development (UNCED: the Earth Summit) in Rio de Janeiro, Brazil in 1992. The theme of this document is sustainable development as a focus for addressing the pressing problems of today and preparing the world for the challenges of the next century. Agenda 21 covers all issues that have significant bearing on one or more of the four key dimensions of sustainability, namely social, economic, environmental and institutional. One of these significant issues is energy [2].

Energy is central to improved social and economic welfare, and is indispensable to most industrial and commercial wealth generation. It is key for relieving poverty, and raising living standards. However, as essential as it may be for development, energy is only a mean to an end. Much of the current energy supply and use is based, on limited resources of fossil fuels which is deemed to be environmentally unsustainable. There is no energy production or conversion technology without risk or without waste. Somewhere along all energy chains — from resource extraction to the provision of energy services pollutants are produced, emitted or disposed of, often with severe health and environmental impacts [2].

The importance of energy in sustainable development is related to three elements. First, the efficient energy supply is considered one of the basic conditions for economic development as a part of the strategic agenda of any country. Second, various ecological and human disaster of recent decades have close relationship with the energy supply, offering arguments in favor of sustainable development. Finally, it also highlights the need for equity in the energy sector, which can be translated into universal access to energy [6]. 
Up until the industrial revolution, renewable sources of energy (i.e. biomass, sunlight, hydropower and wind) were widely used and since then have been replaced by coal. In midtwentieth century, oil has become widely used, coming to be the main energy source used by mankind. These changes fostered development; however, they are non-renewable sources and have been causing major environmental damage. This development model had an impact into cities, which grew disorderly and chaotic.

We stress the role of local solutions to sustainability issues. Local analysis allows a comprehensive view formed by the proper integration of local and regional solutions. This possibility reinforces the ecological thinking of the "act locally, think globally" and aligns with the local Agenda 21, focused on application in small cities and regions [6].

In this sense, sustainability is however more than just the interconnectedness of the economy, society and the environment. Important though, they are largely only the external manifestations of sustainability [11]. This paper presents a set of sustainable energy indicators of cities considering five dimensions: the economic, social, environmental, territorial and political dimensions (See Figure $1)$.

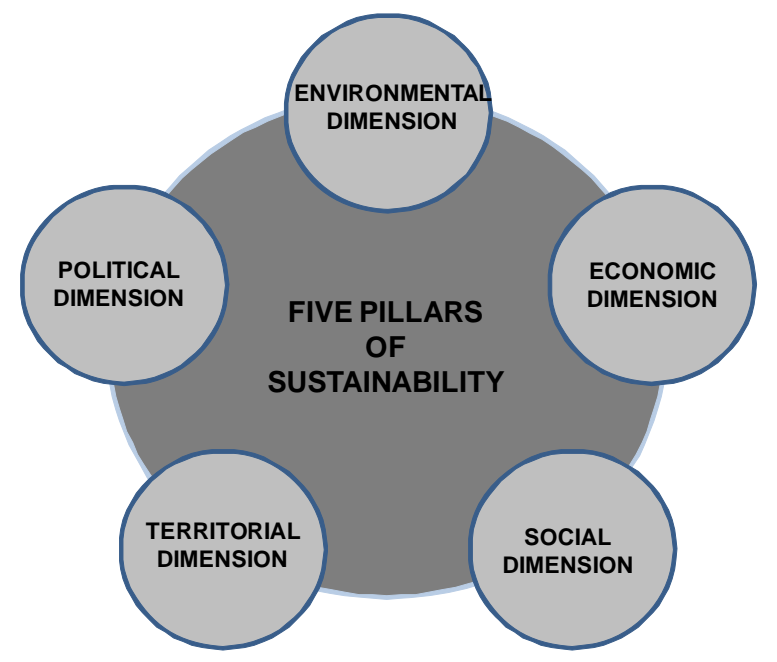

Figure 1. Five Pillars of Sustainability

\subsection{Sustainability Indicators and Energy}

Measuring sustainability is a major issue as well as a driving force for the discussion on sustainable development. Developing tools that reliably measure sustainability is a prerequisite for identifying non-sustainable processes informing design-makers of products' quality and monitoring impacts on the social environment. The multiplicity of indicators and measurement tools being developed in this fast growing field shows the importance of conceptual and methodological work in this area [7] [8].

Measures of sustainability tend to be an amalgam of economic, environmental and social indicators. The first two are responsible, but with difficulty, for the quantitative measurement as they can be expressed in biophysical terms.
There is a tendency to express social indicators in such terms too, but with less success. There is therefore a tendency to see sustainability only in biophysical terms [11].

Indicators are variables. A variable is an operational representation of an attribute or characteristic of a system; it can convey information on the condition and/or trend of an attribute of the considered system [9].

The indicators are not merely data; rather, they extend beyond basic statistics to provide a deeper understanding of the main issues and to highlight important relations that are not evident using basic statistics. They are essential tools for communicating energy issues related to sustainable development to policymakers and to the public, and for promoting institutional dialogue. Each set of indicators expresses aspects or consequences of the production and use of energy. Taken together, the indicators give a clear picture of the whole system, including interlinkages and trade-offs among various dimensions of sustainable development and longe-term implications of current decisions and behaviour. Changes in the indicator values overtime mark progress or lack of it towards sustainable development [2].

We consider the recommendations from the World Resources Institute (WRI) to define the set of sustainable energy indicators [10]:

- Representativeness (to represent the relevance of the product or process identified);

- $\quad$ Comparability (to be comparable in both space and time);

- $\quad$ Data collection (there must be reliable sources to supply the data);

- Clarity and synthesis (to transmit information in a simple synthesis being identified);

- $\quad$ Forecast and Targets (to anticipate problems and seeking solutions being instrumental in setting targets).

\section{Methodology}

The methodology for the development of model has three phases: 1) definition of indicators from a review of previews studies and group discussion; 2) validation of indicators with experts; 3) definition of importance for each indicator in the index of sustainable energy of city.

The monitoring of sustainability is a long term exercise. We need to be flexible, for our ideas and preferences will change with time. The criteria and preferred indicators could be different for the groups who will choose and use them. In this sense, the expert systems could be appropriate [11].

We identified different concepts and dimensions in the literature [11]. However, considering the cities' context, we decided to use the Sachs's dimensions for sustainability in this model [4]. The author presents five pillars: economic, social, environmental, territorial and political. During this first phase, we proposed a set of 26 indicators of energy sustainability for cities. 
The notion of measuring overall sustainability is a daunting task. For this reason, it will probably require teams of experts in many different disciplines to define and determine sustainability indicators. Then, we validated the indicators of 27 experts in sustainability from different areas (See Figure 2).

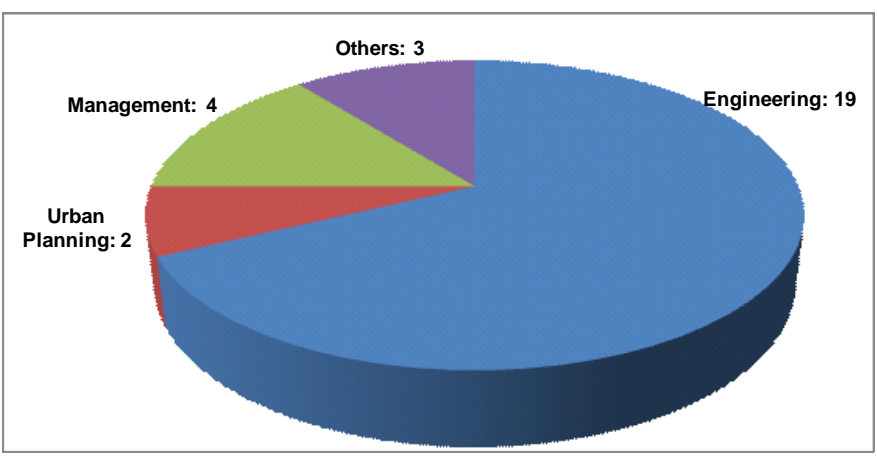

Figure 2. Areas of Experts

The 27 experts were distributed in four groups (Figure 2). The most important group was Engineering (19 experts), followed by Management (only 4 experts). This picture could be a limitation of research's results.

These experts defined the importance of each indicator. The second phase consisted in elaborating a questionnaire to evaluate the importance of each indicator. Finally, we analyzed the data. The next section presents the results.

\section{Results}

We proposed 26 indicators and classified them into five dimensions (environmental, economic, social, territorial and political). The dimensions use likert scales to measure the degree with which the interviewees agree or disagree with each affirmative.

The test did not indicate a significant difference in average. Then, we decided to maintain all indicators, but assigning different weights. The Table 1 presents the list of indicators and each weights.

Table 1. Weights of Indicators

\begin{tabular}{|l|r|}
\hline \multicolumn{2}{|l|}{ ENVIRONMENTAL } \\
\hline Production of reusable waste & $4,26 \%$ \\
\hline Production of toxic waste & $4,19 \%$ \\
\hline Environmental Conditions & $3,65 \%$ \\
\hline $\begin{array}{l}\text { Training and/or education of employees in } \\
\text { environmental issues }\end{array}$ & $3,79 \%$ \\
\hline Waste recycling, collection, treatment and reuse & $4,23 \%$ \\
\hline Energy generation versus energy demand indicates & $4,41 \%$ \\
\hline $\begin{array}{l}\text { ENVIRONMENTAL DIMENSION TOTAL } \\
\text { WEIGHT }\end{array}$ \\
\hline ECONOMIC & $\mathbf{2 4 , 5 3 \%}$ \\
\hline Energy generation x Energy demand & $3,68 \%$ \\
\hline Projected Demand & $3,83 \%$ \\
\hline Investment Capacity & $3,54 \%$ \\
\hline
\end{tabular}

\begin{tabular}{|c|c|}
\hline Control of environmental liability & $3,72 \%$ \\
\hline Environmental protection expenditure & $3,43 \%$ \\
\hline Economic Growth & $3,11 \%$ \\
\hline Local economy basis & $3,72 \%$ \\
\hline $\begin{array}{l}\text { ECONOMIC DIMENSITON TOTAL } \\
\text { WEIGTH }\end{array}$ & $25,04 \%$ \\
\hline \multicolumn{2}{|l|}{ SOCIAL } \\
\hline $\begin{array}{l}\text { Program to encourage the conscientious use of } \\
\text { energy }\end{array}$ & $3,79 \%$ \\
\hline Household income per capita & $3,03 \%$ \\
\hline $\begin{array}{l}\text { Existence of technical training schools and/or } \\
\text { higher }\end{array}$ & $3,97 \%$ \\
\hline SOCIAL DIMENSION TOTAL WEIGHT & $10,80 \%$ \\
\hline \multicolumn{2}{|l|}{ TERRITORIAL } \\
\hline Municipal environmental zoning & $3,68 \%$ \\
\hline Master plan zoning & $3,94 \%$ \\
\hline Raw materials and logistic mobility & $3,25 \%$ \\
\hline Territorial occupation density & $3,61 \%$ \\
\hline Geoprocessing systems & $3,18 \%$ \\
\hline $\begin{array}{l}\text { TERRITORIAL DIMENSION TOTAL } \\
\text { WEIGHT }\end{array}$ & $17,67 \%$ \\
\hline \multicolumn{2}{|l|}{ POLITCAL } \\
\hline Government actions to develop renewable energies & $3,54 \%$ \\
\hline $\begin{array}{l}\text { Actions of local government to generate } \\
\text { employment and income }\end{array}$ & $3,40 \%$ \\
\hline Guidelines and policies of the city's master plan & $3,97 \%$ \\
\hline Guidelines and policies of the environmental plan & $3,65 \%$ \\
\hline Environmental management systems (SGA) & $3,76 \%$ \\
\hline $\begin{array}{l}\text { Municipal environmental Council or Management } \\
\text { Committee of the EMS }\end{array}$ & $3,65 \%$ \\
\hline POLITICAL DIMENSION TOTAL WEIGHT & $21,97 \%$ \\
\hline TOTAL & $100,00 \%$ \\
\hline
\end{tabular}

The next sections describe the indicators in each dimension.

\subsection{Environmental Dimension}

Regarding to Environmental Dimension, we proposed six indicators. The first is 'production of reusable waste'. It indicates whether or not there is considerable impact on the locality in relation to the production of reusable waste, which can be solid, liquid or gaseous.

Second, 'production of toxic waste', that indicates whether or not there is considerable impact on the locality in relation to the production of toxic waste.

'Environmental conditions' indicates whether or not there are environmental restrictions in place that will prevent the exploitation of potential energy. 
'Training and/or education of employees in environmental issues' indicates the city's investment in staff training in relation to the environmental issues.

'Waste recycling, collection, treatment and reuse' evaluates whether or not there is legislation for the development of actions and projects for waste recycling, collection, water treatment and reuse.

The most important indicator in environmental dimension is 'production of reusable waste' and 'waste recycling, collection, treatment and reuse'. This result indicates the importance of energy and waste system of city to reach the sustainable development.

\subsection{Economic Dimension}

The Economic Dimension covers seven indicator related to planning, investment in environmental and economic performance of city.

'Energy generation versus energy demand' indicates whether or not there is local production of electricity and how much this represents in total consumption in the locality, that is, if the energy balance is positive.

'Projected demand of consumption of energy' indicates whether or not there are prospects for increase in demand related to the transformations of productive activity in that territory.

'Environmental protection expenditure' indicates whether or not the city has any expenditure on environmental protection.

'Investment capacity' refers to the city's capacity to invest in new projects through the debt ratio versus Gross Domestic Product (GDP).

'Control of environmental liability' evaluates whether or not there is a municipal control of environmental liabilities resulting from public and private economic activities in the municipality.

'Economic Growth' indicates the municipality's economic growth through the evolution of local GDP in the last ten years in relation to state GDP and national GDP.

'Local economy basis' indicates the participation of different economic activities (primary products, industrial services and trade) in the local GDP.

In economic dimension, the most important indicator was 'projected demand of consumption of energy', following by 'control of environmental liability' and 'local economy basis'. The experts indicate that the projected demand and control of environmental liability is a important element for sustainability, but the challenge is how to measure the environmental liability.

\subsection{Social Dimension}

In Social Dimension, we considered three indicators. The first is the 'program to encourage the conscientious use of energy', that indicates whether the municipality encourages information and knowledge sharing about the need for rational and efficient use of energy.
Second, 'household income per capita' evaluates the income per capita in the municipality.

Third, the 'existence of technical training schools and/or higher' indicates the availability and access to skilled labor. The last one was considered the most important in Social Dimension.

In this way, the experts stress the necessity of technical education to prepare local population to participate in sustainable energy projects. The education for conscientious use of energy is also important.

\subsection{Territorial Dimension}

The Territorial Dimension included five indicators. The most important is 'master plan zoning', that indicates the organization of the city in relation to urban, commercial, industrial and rural areas. It will reflect on the development of projects and actions aimed at sustainable use of energy in the localities.

The 'municipal environmental zoning' analyses whether or not there is the zoning of environmental characteristics and their uses and activities.

'Raw materials and logistic mobility' indicates whether or not the logistics of raw materials interferes with the mobility of the municipality.

'Territorial occupation density' indicates the density of population in the city.

'Geoprocessing systems' refers to the existence and the use of geoprocessing systems in the city.

Considering the territorial dimension, the experts appointed that the urban planning performances an important role in the sustainability of cities.

\subsection{Political Dimension}

The last dimension is the Political. This dimension considers six indicators, which included the evaluation of action, guidelines and policies of the city.

'Government actions to develop renewable energies' evaluates whether or not the municipal government encourages, develops projects, invests and operates in the generation of renewable sources for the development and exploitation of local energy potential.

'Actions of local government to generate employment and income' indicates whether or not there are municipal actions fornew jobs generation and income.

'Guidelines and policies of the municipal environmental zoning' indicates if the society, the community and the government have an interest in taking advantage of renewable energy as an alternative development.

'Guidelines and policies of the environmental plan' indicates whether or not there is in a municipality and a zoning system for managing potential areas for exploration of energy sources.

'Environmental management systems (EMS)' refers to the existence of a municipal environmental management system. 
'Municipal environmental Council or Management Committee of the EMS' indicates the existence of an open, integrated and democratic environmental management system.,

Confirming the results of last dimension, the most import indicators in political dimension were guidelines and policies of the environmental and the EMS. The commitment of local government to foster and support renewable energy projects is fundamental to the sustainable energy development of city.

\section{Conclusion}

The discussion on sustainability is part of the process of working towards a sustainable environment. However, we won't know if we are becoming more sustainable without finding a way to measure it [11].

This paper aimed to present a set of indicators to assess sustainable energy in cities. We proposed 26 indicators of five dimensions (environmental, economic, social, territorial and political). We validated by experts from different areas and each indicator obtained a weight. We also identified the key indicators in each dimension. The analysis of these five dimensions could help policymakers to foster sustainable energy development in cities.

This research was conducted in the Brazilian context, an emerging economy. In these economies, sustainable energy has become central to maintain the country's growth. The results are the first step in order to develop an index of sustainable energy of cities. Further research should apply these indicators to evaluate cities in different contexts. This index could be also useful to policymakers and managers to analyze the level of sustainable energy devolvement of cities.

\section{Acknowledgements}

This study was supported by the following project: Sustainable Energy and Local Development, funding by R\&D Program of National Agency of Electric Energy and Electrical Energy Company of Rio Grande do Sul (Programa $P \& D$ ANEEL CEEE), Brazil.

\section{References}

[1] World Commission on Environment and Development WCED (1987) Our Common Future.Oxford, UK: Oxford University Press.

[2] International Atomic Energy Agency (2005) Energy Indicators For Sustainable Development: Guidelines And Methodologies. Viena.

[3] Silva, C. L.; Lima, J. E. S. (2010) Políticas públicas e indicadores para o desenvolvimento sustentável. São Paulo: Saraiva.

[4] Sachs I. (2004) Desenvolvimento: includente, sustentável, sustentado. Rio de Janeiro: Garamond.

[5] Munier, N. (2011) Methodology to select a set of urban sustainability indicators to measure the state of the city, and performance assessment. Ecological Indicators, vol. 11, pp. 1020-1026.
[6] Reis, L.B.; Fadigas, E.A.; Carvalho, C.E. (2005) Energia, recursos naturais e a pratica do desenvolvimento sustentável. Barueri: Manoele.

[7] Afgan, N.H.; Carvalho, M.G.; Hovanov. N.V. (2000) Energy system assessment with sustainability indicators. Energy Policy, vol. 28, pp. 603 - 612.

[8] Voinov, A.A. (1997) Paradox of Sustainability. Institute for Ecological Economics, Solomons, USA.

[9] Manzini, F.; Macías, J.I.P. (2011) Model for evaluating the environmental sustainability of energy projects. Technological Forecasting \& Social Change, vol. 78, pp. 931-944.

[10] World Resources Institute - WRI (1998) World Resources 1998-99: Environmental change and human health.

[11] Fricker, Alan. Measuring up to Sustainability. http://www.metafuture.org/articlesbycolleagues/AlanFric ker/Measuring\%20up\%20to\%20Sustainability.htm. $\quad$ (28 January 2011). 